\title{
Optimization of Cylindrical Grinding Process- A Review
}

\author{
Miss Pranali P. Patil ${ }^{1}$, Prof. Pravin L. Jadhav ${ }^{2}$ \\ Dept of Mechanical Engineering, Karmaveer Bhaurao Patil College of Engineering, Satara, Maharashtra, India ${ }^{1,2}$
}

\begin{abstract}
Grinding is the machining process which improves dimensional accuracy and improves surface quality. Cylindrical grinding is process of final finishing operation. During this review work input process parameters are cutting speed, feed rate, depth of cut, material hardness, grinding wheel speed, grain size, conditions used and to achieve optimize process parameters Taguchi optimization technique with L9,L18 array used for design of experiment. This study provides a review on optimization of machine parameters by different techniques.
\end{abstract}

Keywords: Grinding, Cylindrical grinding, Surface roughness, Material removal rate, Optimization, Taguchi.

\section{INTRODUCTION}

Grinding is machining process to improve surface quality and dimensional accuracy of the workpiece. Grinding is most widely used finishing process among all traditional process which is used in production. Grinding is a material removal process and surface generation process for shape and finish the component. From grinding process surface finish and precision obtained is very high. Grinding affects the product quality and assembly process. Grinding has been used for metallic materials such as hardened tool tungsten carbide, steel, ceramic material like silicon nitride, alumina, super alloys used in aerospace industry and zirconia. Grinding also is the fabrication process of several newer and lesser known materials like carbon, bulk amorphous metals, metallic foams, ceramic magnets, composite materials and intermetallics. With grinding these materials should be interested in effective cost of grinding process while maintaining required dimensional tolerance, surface characteristics and mechanical properties grinding process interface material removal by contact between grinding wheel and structural surface of the workpiece. Surface quality is main criterion in grinding process. Grinding is large and diverse area of tool making and manufacturing. It is better suited to the machining of hard materials. The material removal rate of the grinding process is much lower compared to the other machining process working with defined tool geometry.

Grinding process used to bring workpiece dimensions within very close tolerance after all the rough finishing and heat treatment operations have been carried out and also used for sharpening the carbide tool. Grinding machines are designed principally to finish parts having cylindrical, flat or internal surface. The kind of surface finish largely depends on the type of grinding machine, according to the quality of surface finish classified as rough grinder and precision grinder. The main purpose of rough grinder is to remove stock without any references to the accuracy of the results. Precision grinders produce good surface finish with high degree of accuracy.

Cylindrical grinding, internal grinding, surface grinding, tool and cutter grinding are the types of precision grinding process. In grinding cooling is preferable then lubricity as high amount heat developed due to high speed rotation of grinding wheel. Coolant improves tool life and surface finish.

\section{CYLINDRICAL GRINDING}

Cylindrical grinding is a type of machine used for grinding cylindrical surface, although tapered and simple formed surface also is ground. The cylindrical grinder work on a variety of shapes. The object must have control axis of rotation. The work is held rigidity in between the centre, in a chuck or in a suitable holding fixture. The work rotates in its axis and a revolving wheel is fed against it. Cylindrical grinding machine are of two types centre type and Centreless type. In centre type of machine work piece is usually held between two dead centres and rotated by a dog and driver on the face plate. The work may also rotate about its own axis in a chuck. The rotating grinding wheel is to be fed towards the work for successive cuts.

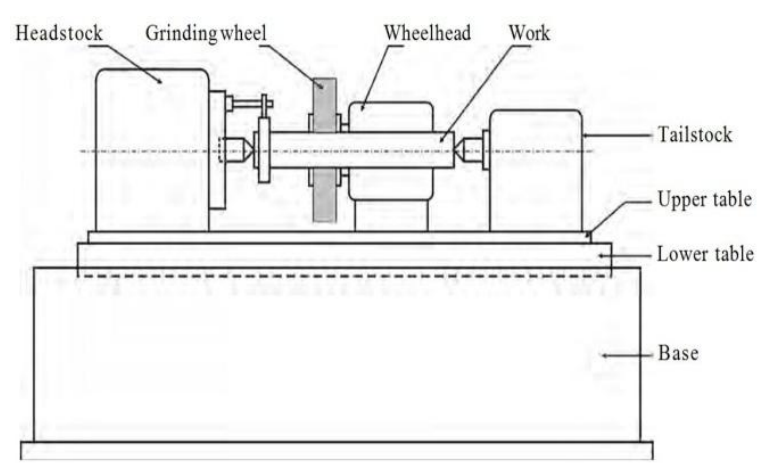

Fig.1 Cylindrical grinding machine

The depth of cut is determined by the feed of the wheel or workpiece. In Centreless type of machine Centreless 
IARJSET

International Advanced Research Journal in Science, Engineering and Technology

National Conference on Design, Manufacturing, Energy \& Thermal Engineering (NCDMETE-2017)

AGTI's Dr. Daulatrao Aher College Engineering, Vidyanagar Extension, Karad

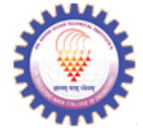

Vol. 4, Special Issue 1, January 2017

grinding is method of grinding exterior cylindrical, tapered tool and cutter grinding machine with L9 orthogonal array. and formed surface on workpiece that are not held and Input machining variables are material hardness, rotated on centres. Principal parts of this are grinding workpiece speed and grinding wheel grains. The wheel, regulating wheel and work rest. Both wheels are workpiece material used for experiment is EN24, EN31, rotated in the same direction. The work is placed upon the die steel. Taguchi method used for optimization process work rest and the latter, together with regulating wheel is parameters. It is found that an optimal value of surface fed forward facing the work against the grinding wheel. roughness for cylindrical grinding process is $1.07 \mathrm{Ra}$. the The various input parameters of cylindrical grinding surface roughness decreases when speed is changed from machine are depth of cut, work piece speed, material 100 to $160 \mathrm{rpm}$. When grinding wheel grains changed hardness, grinding wheel speed, wheel diameter, lead of from G46 to G60, surface roughness decreases.[2]

dressing and number of passes. The output variables 3) K. Mekala et al. proposed experimentation on austenite includes grinding force, surface roughness, thermal damage, specific grinding energy, machine stiffness, material removal rate, dimension accuracy and tool wear. The workpiece materials used for cylindrical grinding are alloy steel, austenite stainless steel, oil hardening non shrinking die steel, and mild steel. Grinding wheel materials used for process are aluminium oxide, silicon carbide, white aluminium oxide, ceramic aluminium oxide, and diamond and boron nitride. To understand the mechanism included in cylindrical grinding process. To study effect of cylindrical grinding process parameters, conditions and optimize for enhancement of output variables.

\section{LITERATURE REVIEW}

The literature review focuses on study done on related journal papers and articles. The literature covers the cylindrical grinding process related to input parameters and machining parameters on output response parameters using optimization techniques.

1) L. P. George et al. done experimental work of cylindrical grinding machine to understand the cutting mechanisms. To study effect of cutting speed, depth of cut and material hardness on surface roughness with taking other parameters set constant. To create an empirical relation between surface roughness value obtained and process parameters. The experiments conducted on MILANO RICEN RUM 1 cylindrical grinding machine with L9 orthogonal array. Surface roughness is measured using MITUTOYO surf test SJ-400 surface roughness tester. Workpiece material used alloy steel of various compositions brought from EMVEE agencies. EN32, EN31, EN353 are the grades of alloy steel have been used with $32 \mathrm{~mm}$ diameter and $300 \mathrm{~mm}$ length in form of rods. Carborundum grinding wheel AA46K5V40 is used as grinding wheel. Soluble oil used as cutting fluid. Taguchi optimization technique is used for optimization of process parameters. It is found that there is decrease in surface roughness as material hardness increased. The surface roughness decreases when speed increases from 60 to 120 rpm. Also Surface roughness decreases when depth of cut increases from 10 to 20 micron. [1]

2) D. Pal et al. did experimental investigation results of surface roughness with cylindrical grinding process parameters. The experiments are conducted on universal

stainless steel rod (AISI 316) using cylindrical grinding machine. The input factors are cutting speed, depth of cut and feed rate. Taguchi design of experiment of L9 orthogonal array used. The experiment is optimized by ANOVA and S/N ratio. The output parameters are metal removal rate and surface roughness. The workpiece material was AISI 316 in the form of round rods with $50 \mathrm{~mm}$ diameter and $70 \mathrm{~mm}$ length. The metal removal found as cutting speed of $560 \mathrm{~m} / \mathrm{min}$, depth of cut of $0.05 \mathrm{~mm}$ and feed of $0.130 \mathrm{~mm}$. It is found that cutting speed is a dominating parameter whereas depth of cut is better for grinding result. [3]

4) M. Melwin et al. performed experimentation on OHNS steel (AISI 0-1) rounds using cylindrical grinding machine. Surface quality of OHNS steel is to be studied in the experiment work using L9 orthogonal array for three levels. Work speed, depth of cut and number of passes are considered as input parameters and response parameter is material removal rate. The work material OHNS steel with $25 \mathrm{~mm}$ diameter and $70 \mathrm{~mm}$ length in the form of round bars. IT is found that optimum parameter of metal removal rate of OHNS steel cylindrical rounds were $0.02 \mathrm{~mm}$ depth of cut, $150 \mathrm{rpm}$ of work speed, and 1 number of pass during experiment. [4]

5) N. Kumar et al. investigated the effect of optimized machine parameter on surface roughness in cylindrical grinding for $\mathrm{C} 40 \mathrm{E}$ steel using optimizes Taguchi technique. During experiment input process parameters are work speed, depth of cut and feed is optimized using L9 orthogonal array. Surface roughness is measured by using MITUTOYO surftest SJ-210 surface roughness tester. Experimental results obtained as for minimum surface roughness grinding speed $210 \mathrm{rpm}$, depth of cut $0.04 \mathrm{~mm}$ and feed $0.11 \mathrm{~mm} / \mathrm{rev}$. The optimized minimum surface roughness obtained is $0.238 \mu \mathrm{m}$. [5]

6) K. Kumar et al. did experimental work for optimal material removal and effect of process parameters of cylindrical grinding machine. The method used for experiment is Taguchi optimization technique. The grinding parameters evaluated are depth of cut and cutting speed. Process analysed by ANOVA. The output process parameter is material removal rate. The mild steel is used as workpiece material having $29.12 \mathrm{~mm}$ diameter and $50.5 \mathrm{~cm}$ length. It concluded that optimal grinding conditions for material removal rate are cutting speed $41.07 \mathrm{~m} / \mathrm{min}$, depth of cut of $0.020 \mathrm{~mm}$ and optimal material removal rate is $19.906 \mathrm{~mm}^{3} / \mathrm{sec}$. [6] 
IARJSET

International Advanced Research Journal in Science, Engineering and Technology

National Conference on Design, Manufacturing, Energy \& Thermal Engineering (NCDMETE-2017)

AGTI's Dr. Daulatrao Aher College Engineering, Vidyanagar Extension, Karad

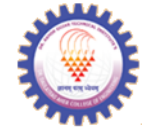

Vol. 4, Special Issue 1, January 2017

7) P. V. Kolhar and R.G. Mench studied optimization of oxide wheel having wheel speed 1100rpm, depth of cut process parameters in grinding process at three levels to $18 \mu \mathrm{m}$ and table speed $3 \mathrm{~m} / \mathrm{min}$. It is observed that Silicon study the non-linearity effect of parameters. Taguchi Carbide (SiC) type wheel gives minimum surface method based L9 orthogonal array was selected for design roughness and Aluminium Oxide wheel gives better of experiment. Based on signal to noise ratio analysis material removal rate. [11]

optimal process parameters have been determined. The experiment had done for reduce rework in case of piston. The input process parameters included cutting speed, feed rate, depth of cut and material hardness. EN8 alloy steel used for workpiece material. It is found that rework in assembly line is reduced from optimal level settings of process parameters. Reducing depth of cut rework can be reduced in assembly line.[7]

8) Z.A. Khan et al. Studied effective approach for optimization of an in-feed Centreless cylindrical grinding of RN52 austenitic steel with multiple performance characteristics based on grey relation analysis. Taguchi method of L9 orthogonal array was used for experiment. The input process parameters are dressing feed, grinding feed, and cycle time. The output performance parameter is surface roughness and out of cylindricity. It is observed that optimal performance characteristics of the lowest surface roughness and out of cylindricity obtained from process parameters. The greatest grey relation value obtained 0.9745 . The optimal performance characteristics achieved with grinding feed $6 \mathrm{~mm} / \mathrm{min}$, dwell time $2.5 \mathrm{sec}$, dressing feed $5 \mathrm{~mm} / \mathrm{min}$ and cycle time $11 \mathrm{sec}$. [8]

9) M. Ganesan et al. Performed experimentation of optimization of the grinding parameters for surface roughness in cylindrical grinding machine by using Taguchi's design of experiment and ANOVA method to optimization. The input process parameters are cutting speed, feed rate and depth of cut. The materials for work piece are 304 stainless steel and for grinding wheel $\mathrm{SiC}$ type. The design of experiment of L9 orthogonal array has been used. It is found that optimum parameters are $780 \mathrm{~m} / \mathrm{min}$ of cutting speed, $0.05 \mathrm{~mm}$ of depth of cut and $0.093 \mathrm{~mm}$ of feed rate. In this cutting speed is dominating parameter. [9]

10) S.Thakor and D.M. Patel proposed the optimum characteristic on surface finish and metal removal rate using EN 8 alloy steel. The important output response in production with quality. The input parameters are cutting fluids, depth of cut and work piece speed. The software MINITAB is used to drive model between input and output characteristics. The experimentation carried by using $\mathrm{Al}_{2} \mathrm{O}_{3}$ grinding wheel. The soluble oil used as cutting fluid. It is found for optimum parameters surface roughness of $0.4246 \mu \mathrm{m}$ and material removal rate of $0.0974 \mathrm{gm} / \mathrm{sec}$. The optimum result obtained with work piece speed $120 \mathrm{rpm}$ and depth of cut of $500 \mu \mathrm{m}$. [10]

11) P. Kumar et al. done experiment for optimize process parameter on surface roughness and material removal rate using alloy steel EN 24 on $\mathrm{CNC}$ grinding machine. The experiment carried out using $\mathrm{Al}_{2} \mathrm{O}_{3}$ and $\mathrm{SiC}$ type wheel material. The input process parameter taken as depth of cut, wheel speed and table speed. The result gives the optimum machining parameters found using aluminium

12) D.Pai et al. Studied optimised machine parameters on surface roughness in cylindrical grinding. The material used for experimentation is Al-Si (MMC) type. The input parameters are material hardness, depth of cut and flow rate for experiment L27 orthogonal array is used. The surface roughness has been measured for machining of MMC specimen at different cutting conditions. It is observed that increase in the hardness of material improves surface finish of material. [12]

13) M.Kumar et al. done experiment for optimise the effect of input variables to minimise the surface roughness and maximum material removal rate in cylindrical grinding of alloy steel EN 47 material. The Taguchi L18 orthogonal array method used for experiment. The input parameters are wheel speed, work speed, grain size, and depth of cut, flow rate and number of passes. It is found that $\mathrm{S} / \mathrm{N}$ ratio increases when work speed increases from $224 \mathrm{rpm}$ to $450 \mathrm{rpm}$ and decreases when grain size changed 36 mesh/inch $\mathrm{S} / \mathrm{N}$ ratio is higher at depth of 30 micrometer which maximum material removal rate and minimum surface roughness.[13]

14) S. Kumar et al.done analysis and optimisation of cylindrical grinding process parameters on material removal rate of EN15AM steel for design of experiment Taguchi method used to optimise the cylindrical grinding parameters. The input parameters are wheel speed, work speed, feed and depth of cut. Work piece material EN15AM having diameter $30 \mathrm{~mm}$ and $380 \mathrm{~mm}$ length round bar was used. The optimal result obtained for material removal rate are grinding wheel speed 1800rpm, work piece speed $155 \mathrm{rpm}$, feed rate $275 \mathrm{~mm} / \mathrm{min}$ and depth of cut $0.04 \mathrm{~mm}$. [14]

15) Halil Demir et al. studied the effect of grinding wheel and depth of cut on material removal rate and depth of cut of AISI 1050 steel material. The input parameters are depth of cut, grinding wheel revolution, wheel dressing rate and coolant floe rate. It $\mathrm{s}$ found that result gives lowest surface roughness as grain size of 80 , low grain number wheel used for large volume chip removal operation. The surface roughness increases with depth of cut increased. [15]

16) R. Rekha and N. Baskar studied modelling and optimisation of cylindrical grinding process of Al-Si316 stainless steel. Experimental work done using neural network (NN) and genetic algorithm (GA) for modelling and optimising the process parameters. The experiment conducted by taking input parameters cutting speed, feed rate, depth of cut and machining performance. The output parameters are surface roughness and metal removal rate. The developed model able to predict metal removal rate and surface roughness. The accuracy of neural network model is less. [16] 
IARJSET

\section{CONCLUSION}

From above literature review, it has been observed that optimum surface finish and material removal rate obtained with optimum grinding process conditions. Taguchi method used for experiment is best to optimize quality characteristics. ANOVA is best analysis of variance. For analysis of input parameters we can be apply RSM method, ANN method, SEO method of optimization. Also workpiece material alloy steel with checking hardness can be used like EN9, EN30, EN30B, and Austenite stainless steel of grades AISI H13, AISI D3, AISI D2. For tool $\mathrm{Al}_{2} \mathrm{O}_{3}$ and $\mathrm{SiC}$ mostly used but White aluminium oxide, cubic boron nitrite, Ceramic aluminium oxide also used for grinding wheel.Taguchi method can be apply for optimizing machine stiffness, specific grinding energy.

\section{REFERENCES}

1. Lijohn P. George Varghese Job, I.M. Chandran 2013, "Study on Surface Roughness and its Prediction in Cylindrical Grinding Process based on Taguchi method of optimization", International Journal of Scientific and Research Publications, vol. 3, Issue 5, PP 1-5.

2. Deepak Pal, Ajay Bangar, Rajan Sharma, Ashish Yadav (2012), "Optimization of Grinding Parameters for Minimum Surface Roughness by Taguchi Parametric Optimization Technique", International Journal of Mechanical and Industrial Engineering vol1, Issue 3, pp 74-78.

3. K Mekala, J. Chandradas, K Chandraselaran, T T M Kannan, E Ramesh and R Narasing Babu (2014), "Optimization of Cylindrical Grinding Parameters of Austenitic Stainless Steel Rods (AISI 316) by Taguchi Method", International Journal of Mechanical Engineering and Robotics Research, vol. 3, No. 2, pp 1-5.

4. M.Melwin Jagadeesh Sridhar, M.Manickam, V. Kalaiyarasan, (2014) "Optimization of Cylindrical Grinding Process Parameters of OHNS steel (AISI 0-1) Rounds Using Design of Experiments Concept"; IJETT vol. 17, pp-109-114.

5. Naresh Kumar, Himanshu Tripati, Sandeep Gandotra, (2015) "Optimization of Cylindrical Grinding process Parameters on $\mathrm{C} 40 \mathrm{E}$ steel Using Taguchi Method";. ISSN: 2248-9622, vol. 5, Issue 1.

6. Kundan Kumar, Somnath Chattopadhyaya, Hari Singh, (2012). "Optimal Material Removal and Effect of Process Parameters of Cylindrical Grinding Machine By Taguchi Method”. IJAERS/vol. 2.

7. Praveenkumar V. Kolhar, Dr. R.G. Mench, "Optimization of Process Parameters in Grinding Process to Reduce the rework in case of Piston using Taguchi technique"; IPASJ International Journal of Mechanical Engineering (IIJME), vol. 2 Issues 10.pp 1-5.

8. Khan Z.A, Siddique A.N. and KAmaruddin S.(2012); "Optimization of In-Feed Centreless Cylindrical Grinding Process Parameters Using Grey Relational Analysis"; ISSN/vol.2. pp 257-268.

9. M. Ganeshan, S. Karthikeyan \& N. Karthikeyan, "Prediction and Optimization of Cylindrical Grinding Parameters for Surface Roughness Using Taguchi Method", IOSR Journal of Mechanical and Civil Engineering (IOSR-JMCE) e-ISSN: 2278-1684 pp 39-46.

10. Suresh P. Thakor, Prof. Dr. D.M. Patel (2014), "An Experimental Investigation on Cylindrical Grinding Process Parameters for En8 Using Regression Analysis", International Journal of Engineering Development and Research, vol. 2, Issue 2, pp 2486-2491.

11. Pawan Kumar, Anish Kumar, Balinder Singh (2013), "Optimization of Process Parameters in cylindrical Grinding Using Response Surface Methodology", International Journal of Research in Mechanical Engineering \& Technology vol. 3, Issue 2, pp 245-252.

12. Sandeep Kumar, Onkar Singh Bhatiya (2015); "Analysis and optimization of cylindrical grinding process on material removal rate of EN15AM steel". IOSR journals of Mechanical Engineering, vol.12, pp 35-43.

13. Halil Demir, Abdulkadir Gullu, Ibrahim Ciftci (2010), "An Investigation into the Influences of Grain Size and Grinding
Parameters on Surface Roughness and Grinding Forces when Grinding", International Journal of Mechanical Engineering vol.56, pp 447-454.

14. R. Rekha, N Baskar,(2014) "NN-GA Based Modelling and Optimization of Cylindrical Grinding Process"; International Journal of Research in Mechanical Engineering \& Technology, vol 36, pp- 269(1)-269(5).

15. Halil Demir, Abdulkadir Gullu, Ibrahim Ciftci (2010), “An Investigation into the Influences of Grain Size and Grinding Parameters on Surface Roughness and Grinding Forces when Grinding”, International Journal of Mechanical Engineering vol.56, pp 447-454.

16. R. Rekha, N Baskar (2014); "NN-GA Based Modelling and Optimization of Cylindrical Grinding Process" ; International Journal of Research in Mechanical Engineering \& Technology, vol 36, pp- 269(1)-269(5). 